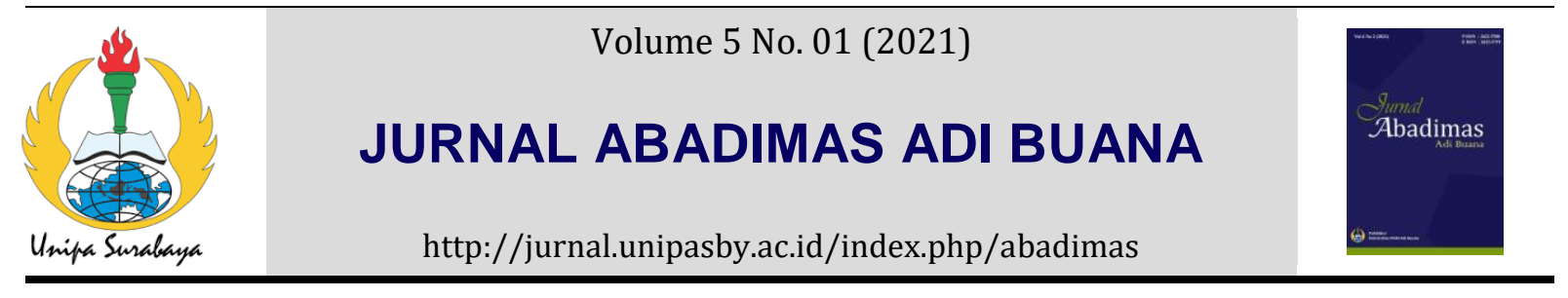

\title{
PERANCANGAN PRODUK KREATIF BERBASIS BUDAYA JAWA TIMUR UNTUK BALAI PELESTARIAN CAGAR BUDAYA JAWA TIMUR (BPCB JATIM)
}

\author{
Shienny Megawati ${ }^{1 *}$, Marina Wardaya ${ }^{2}$, Patrisia Amanda ${ }^{3}$ \\ ${ }^{1}$ Visual Communication Design, Universitas Ciputra, Surabaya, Indonesia \\ ${ }^{3}$ Communication Marketing, Universitas Ciputra, Surabaya, Indonesia \\ *Email: shienny.megawati@ciputra.ac.id
}

\begin{abstract}
Informasi Artikel Abstrak
Kata kunci:

Cagar Budaya Jawa

Timur, Illustrated Book,

Produk Kreatif, Konten

Kreatif

Diterima: 13-01-2021

Disetujui: 19-04-2021

Dipubikasikan: 14-07-

2021

Indonesia memiliki beraneka cagar budaya yang perlu dilestarikan dan dikenalkan kepada generasi muda. Salah satunya adalah Cagar Budaya Jawa Timur dengan 11.155 tinggalan purbakala, yang terdiri dari benda bergerak, benda koleksi museum, bangunan, struktur, hingga kawasan situs dari zaman Prasejarah, Hindu Budha, Islam hingga Kolonial. Balai Pelestarian Cagar Budaya (BPCB) Jawa Timur telah mengkurasi serta mengkatalogkan temuan budaya tersebut dan memerlukan sebuah strategi untuk mensosialisasikan hasil temuan arkeologi berupa cerita rakyat dan cerita fabel. Oleh karena itu BPCB Jawa Timur ingin membuat publikasi arkeologi untuk masyarakat, khususnya anak dan remaja dengan visual yang menarik sesuai selera dan tren, sekaligus mempublikasikannya di sosial media.Tujuan Kegiatan PKM ini adalah menghasilkan rancangan konten kreatif berdasarkan warisan budaya Indonesia untuk BPCB Jawa Timur yang sesuai dengan selera dan tren budaya populer yang digemari oleh masyarakat, serta membuat publikasi konten di sosial media. Metode pelaksanaan yaitu tahap Pra Perancangan menyepakati materi dan konten produk kreatif ilustrated book serta media sosialisasinya. Tahap berikutnya Perancangan yaitu melakukan proses perancangan buku Illustrated Book. Tahap terakhir Publikasi dan Sosialisasi adalah publikasi dan legalitas dari Illustrated Book Pandu Putra Kamajaya yang telah dirancang berupa pengurusan ISBN dan HKI, serta sosialisasi menggunakan media sosial berupa radio streaming dan podcast.
\end{abstract}

\footnotetext{
Abstract

Indonesia has a variety of cultural heritages that need to be preserved and introduced to the younger generation. One of them is the East Java Cultural Heritage with 11,155 ancient remains, consisting of movable objects, museum collections, buildings, structures, to site areas from Prehistoric times, Hindu Buddhism, Islam to Colonial times. The East Java Cultural Heritage Conservation Center (BPCB) has curated and cataloged these cultural findings and requires a strategy to disseminate archaeological findings in the form of folk tales and fable stories. Therefore, the East Java BPCB wants to make archaeological publications for the community,
} 
especially children and adolescents with attractive visuals according to tastes and trends, as well as publish them on social media. The purpose of this PKM activity is to produce creative content designs based on Indonesian cultural heritage for the East Java BPCB which according to the tastes and trends of popular culture favored by the community, as well as making content publications on social media. The implementation method, namely the PreDesign stage, agrees on the material and content of the creative product illustrated book and the media for its socialization. The next stage of design is to carry out the design process of the Illustrated Book. The final stage of Publication and Outreach is the publication and legality of Pandu Putra Kamajaya's Illustrated Book which has been designed in the form of handling ISBN and IPR, as well as socialization using social media in the form of streaming radio and podcasts.

\section{PENDAHULUAN}

Balai Pelestarian Cagar Budaya Jawa Timur adalah lembaga yang bergerak dalam bidang usaha pengelolaan dan pelestarian benda cagar budaya dan situsnya di Provinsi Jawa Timur. Fungsi dan tugas BPCB Jatim meliputi pemeliharaan, perlindungan, pemugaran, dokumentasi dan bimbingan / penyuluhan, penyidikan dan pengamanan baik benda cagar budaya bergerak maupun tidak bergerak(bpcb mojokerto, n.d.). Bagian ini didukung kajian literatur yang dijadikan sebagai penunjang konsep pengabdian. Penulis dituntut menyajikan kajian literatur yang primer (referensi artikel jurnal dan prosiding konferensi) dan mutakhir (referensi yang dipublikasikan dalam selang waktu 10 tahun terakhir). Kajian literatur tidak terbatas pada teori saja, tetapi juga bukti-bukti empiris. Perkaya bagian pendahuluan ini dengan upaya-upaya yang pernah dilakukan pihak lain. Artikel ini merupakan hasil pengabdian yang merupakan hilirisasi dari hasil penelitian, dapat berupa hasil penelitian sendiri maupun peneliti lain.

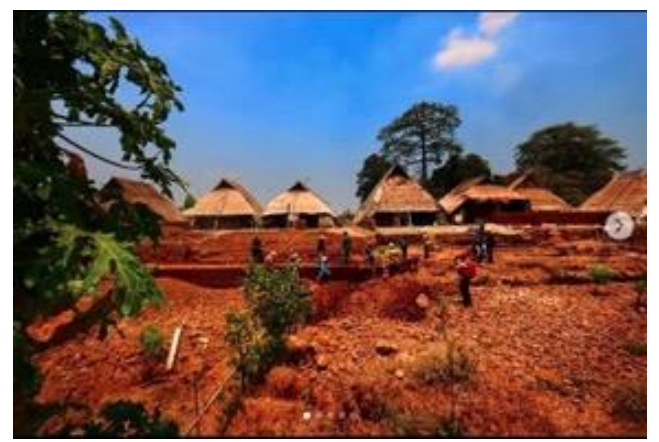

Gambar 1. Ekskavasi BPCB Jatim di Situs Kumitir, Jatirejo, Mojokerto.

Berdasarkan data dari BPCB di provinsi Jawa Timur yang terdiri dari $38 \mathrm{Kota} / \mathrm{Kabupaten}$ terdapat sebaran tinggalan purbakala dari zaman Prasejarah, Hindu Budha, Islam hingga Kolonial. Dari kegiatan Inventarisasi yang dilakukan BPCB sejak tahun 1988 didapatkan data bahwa ada sejumlah 11.155 tinggalan purbakala di wilayah Jawa Timur yang terdiri dari benda bergerak, benda koleksi museum, bangunan, struktu, hingga kawasan situs. 
Balai Pelestarian Cagar Budaya Jawa Timur telah mengkurasi serta mengkatalogkan temuan-temuan budaya tersebut dan kini BPCB Jatim memerlukan sebuah strategi untuk mensosialisasikan hasil temuan arkeologi berupa cerita rakyat dan cerita fabel yang belum banyak diketahui oleh masyarakat umum. Membuat publikasi arkeologi untuk masyarakat, khususnya anak dan remaja dengan visual yang menarik sesuai selera dan tren yang mereka ikuti, sekaligus mempublikasikannya di sosial media.

Dari pemaparan di atas, maka permasalahan yang dihadapi oleh BPCB Jawa Timur dapat dijabarkan menjadi:

1. Mengadaptasi tinggalan arkeologi dan warisan budaya Jawa Timur ke dalam mediamedia populer yang menarik bagi anak dan remaja Indonesia.

2. Memanfaatkan media sosial untuk publikasi konten kreatif dalam rangka memperkenalkan arkeologi dan warisan budaya Jawa Timur.

Untuk menjawab permasalahan itu, BPCB Jawa Timur sebagai pemegang data dan informasi mengenai temuan-temuan arkeologi di Jawa Timur berkolaborasi dengan Jurusan Visual Communication Design (VCD-UC) dan Communication and Communication Marketing Universitas Ciputra (COM-UC) sebagai pendidik dan praktisi dalam bidang industri kreatif untuk mengadaptasi hasil temuan arkeologi tersebut ke dalam budaya populer khususnya yang berbentuk visual seperti ilustrasi atau komik. Informasi dalam bentuk visual lebih mudah ditangkap oleh anak dan remaja, apalagi jika dikemas dalam konten menghibur. Karena itu hasil akhir yang diharapkan dari kolaborasi ini adalah rancangan konten kreatif berdasarkan warisan budaya Indonesia yang sesuai dengan selera dan tren budaya populer yang digemari oleh masyarakat, serta membuat publikasi konten di sosial media

Sehingga dari pemaparan tersebut dapat disimpulkan, tujuan dari kegiatan Program Kemitraan Masyarakat (PKM) ini adalah rancangan produk kreatif berbasis budaya indonesia untuk Balai Pelestarian Cagar Budaya Jawa Timur (BPCB JATIM) yaitu Illustrated Book beserta strategi publikasinya melalui media sosial berupa Podcast Streaming yang akan dijadikan media promosi sekaligus edukasi masyarakat akan peninggalan budaya Indonesia. 


\section{METODE}

Kegiatan Program Kemitraan Masyarakat (PKM) akan dilaksanakan oleh dosen-dosen Program studi Visual Communication Design dan Communication and Communication Marketing Universitas Ciputra sebagai koordinator pengabdian dengan melibatkan mahasiswa semester 5 dan 7 dalam proses riset dan perancangan. Balai Pelestarian Cagar Budaya Jawa Timur (BPCB Jatim) sebagai mitra dalam kegiatan PKM ini akan berpartisipasi sebagai pemateri dan narasumber dalam rangkaian kegiatan perancangan produk kreatif, edukasi, serta sosialisasi yang akan dilakukan. Mitra bersedia meluangkan waktu dan tenaga untuk melakukan sesi client brief perancangan bersama mahasiswa Jurusan VCD-UC, dab sesi-sesi edukasi serta sosialisasi melalui sosial media bersama mahasiswa dan COM-UC.

Pelaksanaan Program Kemitraan Masyarakat (PKM) dilakukan melalui tiga tahap, yaitu Tahap Pra Perancangan, Tahap Perancangan, dan Tahap Publikasi yang akan dijabarkan sebagai berikut:

\section{Tahap Pertama: Pra Perancangan}

Tahap ini melibatkan dosen VCD-UC dan COM-UC selaku koordinator pelaksana PKM dan Ibu Kiki, arkeolog serta perwakilan BPCB Jatim. Kedua pihak menyepakati materi dan konten produk kreatif ilustrated book serta media sosialisasinya. Ilustrated book yang akan dirancang berisikan delapan cerita yang telah disediakan oleh pihak BPCB Jatim, yaitu kisah tentang Putra Pandu atau Pandu Putra Kamajaya. Kisah-kisah tersebut ditemukan melalui hasil ekskavasi dan dokumentasi arkeologi dari situs Candi Penataran dan Candi Jago, antara lain: Arjunawiwaha, Bubuksah dan Gagang Aking, Kresnayana, Kunjarakarma, Parthayajnya, Sang Setiyawan, Sri Tanjung, dan Tantri.

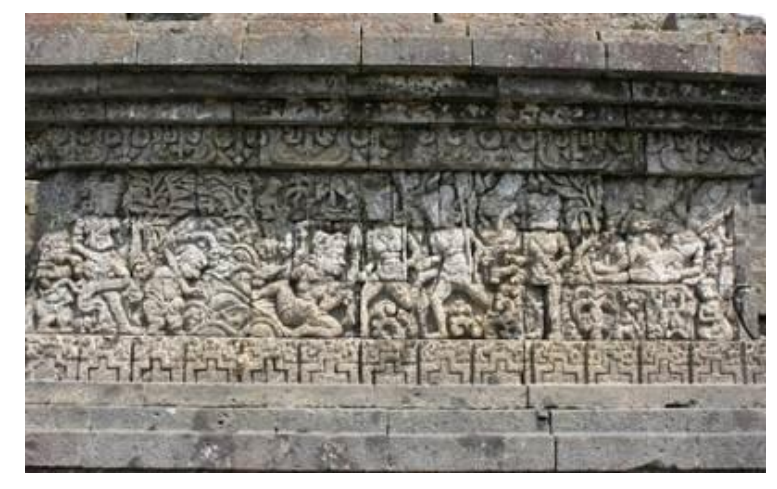

Gambar 2. Relief cerita Kresnayana Candi Penataran 
Setelah menentukan cerita dan menyepakati format hasil akhir Illustrated Book Pandu Putra Kamajaya yang akan dirancang bersama dengan mitra. Hal selanjutnya yang dilakukan adalah menyusun lembar dan modul kerja mahasiswa untuk memastikan agar luaran yang akan dihasilkan sesuai konsep dan pakem cerita dan selesai tepat pada waktunya.

\section{II.Tahap Kedua: Perancangan}

Tahap berikutnya adalah melakukan proses perancangan buku Illustrated Book berdasar naskah folktale Pandu Putra Kamajaya yang telah disediakan oleh BPCB Jatim. Proses perancangan akan dilakukan oleh Mahasiswa VCD UC di Mata Kuliah Concept Design and Illustration (VCD2029) yang akan dilangsungkan mulai minggu ke-hingga tahap pengumpulan karya di minggu ke-15. Seluruh proses perancangan akan disupervisi dan dibimbing oleh Dosen MK Concept Design and Illustration.

III. Tahap Ketiga: Publikasi dan Sosialisasi

Tahap Ketiga dari proses PKM ini adalah publikasi dan legalitas dari Illustrated Book Pandu Putra Kamajaya yang telah dirancang berupa pengurusan ISBN dan HKI, serta sosialisasi menggunakan media sosial berupa radio streaming dan podcast. (podcast, radio)

\section{Tahap Keempat: Evaluasi}

Pada tahap keempat ini dilakukan evaluasi terhadap semua proses dan hasil dari PKM ini, melihat apakah program kemitran ini mencapai sasaran atau tidak, serta mengedukasi masyarakat akan peninggalan budaya Indonesia.

\section{HASIL DAN PEMBAHASAN}

Berikut adalah capaian dari kegiatan - kegiatan pengabdian masyarakat yang telah dilakukan. Hingga artikel ini ditulis (Oktober 2020) Kegiatan-kegiatan yang telah selesai dilaksanakan adalah Tahap Pra Perancangan sebagai berikut:

1. Project Brief dengan Ibu Kiki Arkeolog BPCB Jatim

2. Menetapkan Alur Kerja Perancangan

3. Pembuatan Worksheet dan Modul Perancangan

\section{Pra-Perancangan 1: Project Brief dengan Ibu Kiki Arkeolog BPCB Jatim}

Langkah pertama dalam penciptaan karya ilustrasi grafis adalah project brief (Shinney Sutanto, 2020). Project Brief membantu perancang mengetahui lebih dalam tentang kebutuhan dan ekspektasi klien (dalam hal ini BPCB Jatim) berkaitan dengan hasil akhir 
perancangan yang akan dihasilkan. Beberapa poin-poin penting yang perlu dirangkum dalam proses project brief ini antara lain:

\section{Latar Belakang Klien}

Klien dalam project ini adalah BPCB Jatim. Sebagai organisasi yang bergerak dalam bidang ekskavasi, perservasi tinggalan arkeologi Jawa Timur, BPCB membutuhkan sebuah media untuk melakukan diseminasikan dan publikasi hasil temuan agar dikenal oleh masyarakat khususnya generasi muda.

\section{Unique Selling Proposition (USP)}

USP adalah atau keunggulan yang akan membuat produk rancangan berbeda dari kompetitornya (Mahmud Machfoedz, 2010). Berdasar hasil diskusi dengan BPCB Jatim, diketahui bahwa USP atau keunggulan yang diharapkan untuk Illustrated Book Pandu Putra Kamajaya adalah mengadaptasi folktale hasil temuan arkeologi menggunakan gaya visualisasi budaya populer Sehingga hasil akhir yang dirancang adalah konten kreatif yang edukatif, inspiratif, kreatif dan menghibur.

Salah satu contoh yang populer adalah Komik Petualangan Tintin. Petualangan Tintin atau dalam Bahasa Perancis "Les Aventures de Tintin et Milou" adalah serial komik yang diciptakan oleh Georges Remi atau lebih dikenal dengan nama Hergé, seorang komikus Belgia. Serial Tintin diterbitkan mulai tahun 1929 dan sangat populer karena gaya gambar Hergé yang sangat ekspresif dan dikenal dengan gaya Ligne Claire, selain itu Komik Tintin dikenal karena dibuat berdasarkan riset mendalam oleh pengarangnya sehingga dapat menampilkan kondisi politik dan kebudayaan setiap negara dengan akurat. Komik dengan gaya ligne claire memiliki ciri khas yang menonjol dengan goresan garis yang tegas, serta gambar karakter dengan postur yang semi realis, memiliki background dengan detail, penggambaran efek dalam komik yang sederhana namun jelas, serta pewarnaannya yang menggunakan teknik color block tanpa menggunakan shading(Pinandita, 2016). 


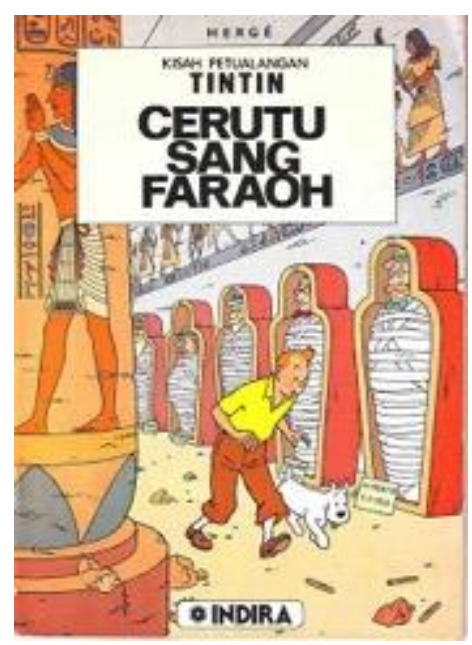

Gambar 3. Contoh Komik Populer yang mengangkat temuan arkeologi

Untuk mempertahankan nilai edukatif dalam konten, maka adaptasi visual folktale Pandu Putra Kamajaya ke dalam visualisasi populer harus tetap dibuat berdasarkan data dan kajian ilmiah supaya hasil adaptasi ke dalam budaya populer tidak bersifat fiktif dan mengada-ada. Karena konten cerita telah disediakan oleh BPCB, maka tugas mahasiswa dalam melakukan perancangan adalah menjaga memperhatikan agar elemen visual yang dirancang sesuai atau terinspirasi dengan referensi awal yang terdapat pada situs-situs arkeologi temuan BPCB. Contohnya relief cerita Arjunawiwaha yang ditemukan pada Candi Jago.

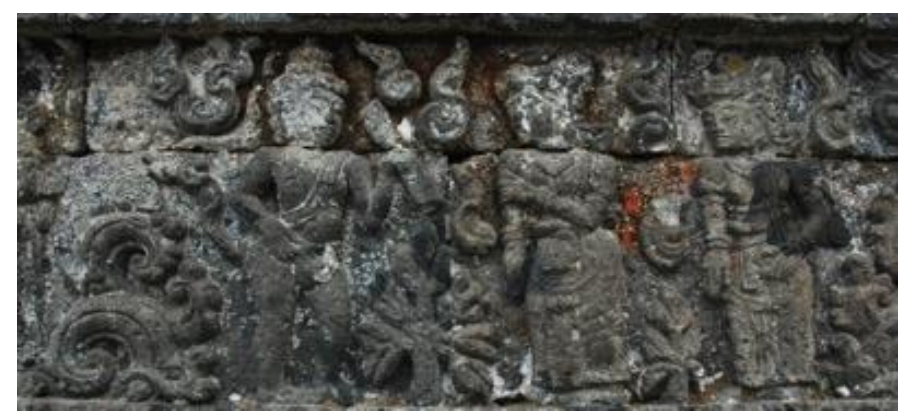

Gambar 4. Relief Cerita Arjunawiwaha di Candi Jago

Berdasar catatan dari hasil meeting dengan Ibu Kiki, maka berapa elemen visual yang harus diperhatikan ketepatannya antara lain: corak, ornamen, hiasan, latar belakang lokasi cerita, dan desain karakter termasuk kostum serta asesoris. 


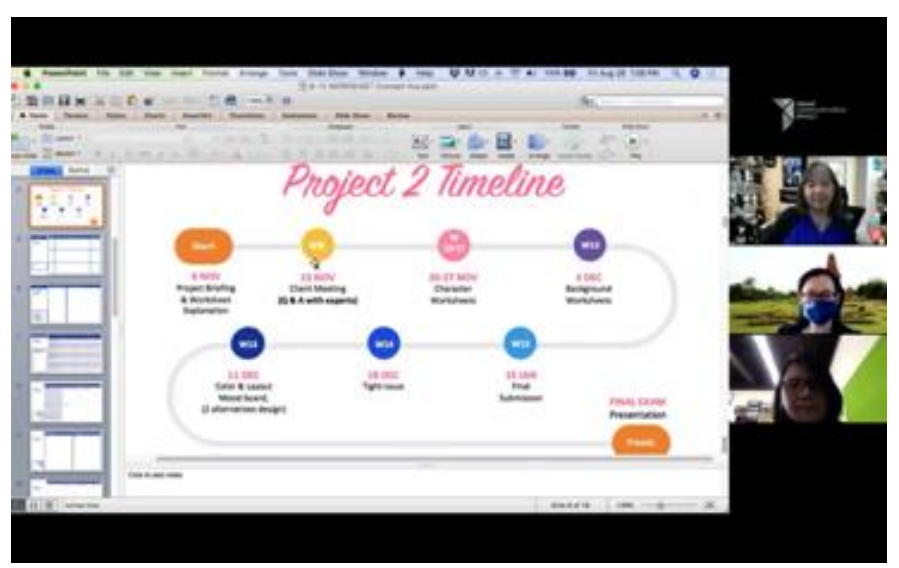

Gambar 5. Diskusi dengan Ibu Kiki arkeolog BPCB

\section{Brand Personality}

Brand personality menurut Kotler sebagai campuran tertentu dari sifat-sifat manusia yang kita dapat atribut untuk merek tertentu (Kotler \& Keller, 2009). Setelah mengetahui tujuan perancangan dan USP dari Illustrated Book folktale Pandu Putra Kamajaya, perlu diketahui juga personality atau kepribadian dari produk yang hendak dirancang. Kepribadian yang ingin ditonjolkan Illustrated Book Pandu Putra Kamajaya adalah daya tarik kehidupan masa lampau, serta misteri dan petualangan.

\section{Khalayak Sasaran}

Yang akan menjadi khalayak sasaran dari Illustrated Book folktale Pandu Putra Kamajaya ini adalah generasi muda, khususnya remaja dan anak-anak usia 8 hingga 13 tahun yang sudah terbiasa menikmati budaya populer seperti komik dan animasi.

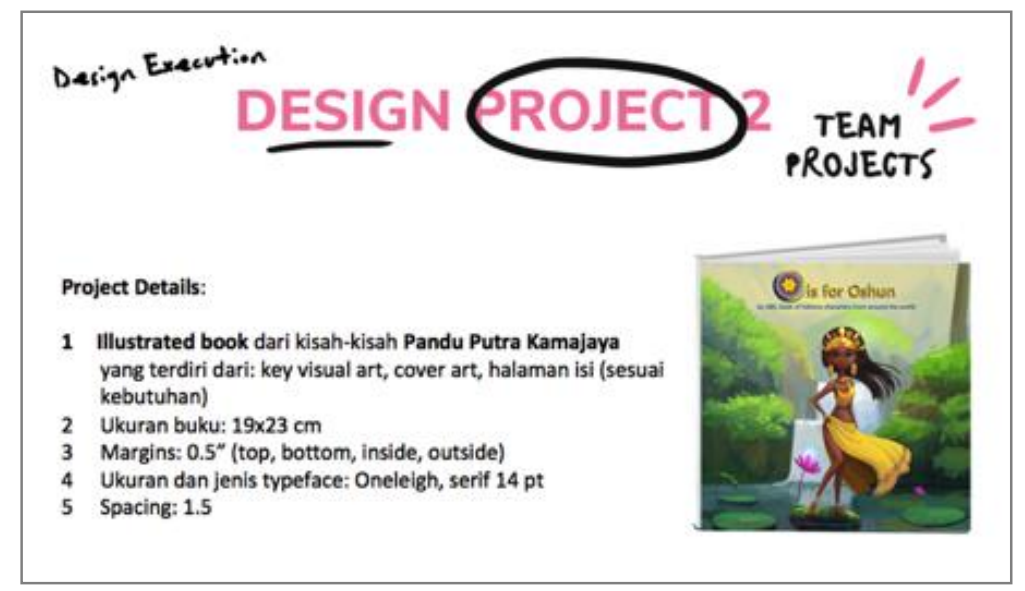

Gambar 6. Brief Project Folktale BPCB 


\section{UCAPAN TERIMAKASIH}

Puji syukur kami ucapkan kepada Tuhan Yang Maha Esa yang telah memberikan rahmat sehingga pelaksanaan pengabdian masyarakat ini bisa berjalan dengan lancar. Untuk itu kami ingin mengucapkan rasa terima kasih yang sebesar-besarnya kepada LPPM Universitas Ciputra yang mewadahi, memfasilitasi sekaligus mendukung keberlangsungan penmas ini.

\section{KESIMPULAN}

Dari keseluruhan tahap pra perancangan mulai dari tahap kreatif brief dengan mitra dan pemilihan worksheet-worksheet yang akan digunakan oleh mahasiswa dalam melaksanakan PKM ini, diketahui bahwa riset merupakan proses paling penting yang harus dilakukan oleh dosen dan mahasiswa pelaksana PKM.

Melalui riset yang intensif dan pemahaman yang kuat akan materi yang hendak diilustrasikan, maka hasil akhir karya yang dihasilkan benar-benar akurat dalam penggambaran tokoh dan setting dari kisah-kisah Pandu Putra Kamajaya. Sehingga hasil akhir yang diperoleh dalam proses PKM ini dapat menjawab kebutuhan atau masalah yang dihadapi mitra PKM BPCB Jawa Timur, yaitu menghasilkan sebuah konten kreatif menggunakan gaya visualisasi budaya populer yang dirancang dengan akurasi visual sesuai hasil temuan arkeologi BPCB Jawa Timur.

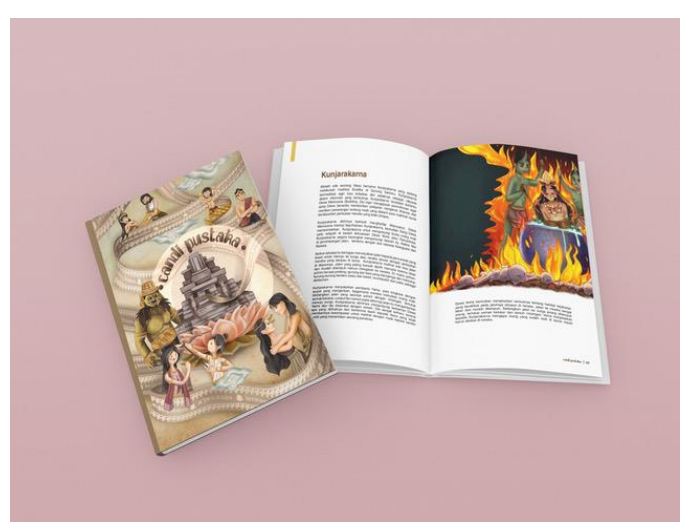

Gambar 7. Hasil Akhir Illustrated Book

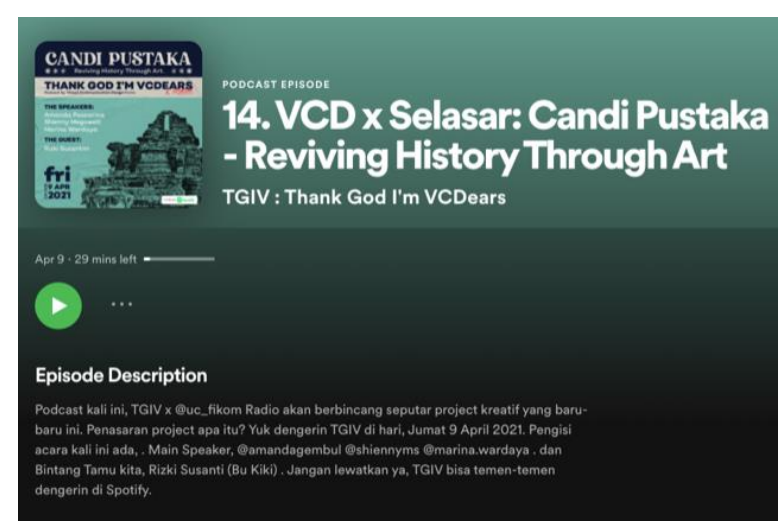

Gambar 8. Cover Podcast

Selain Illustrated Book, juga dilakukan diseminasi hasilnya ke masyarakat Surabaya agar lebih aware mengenai keberadaan candi jago dan kisah-kisah yang terukir di reliefnya, Diseminasi dilakukan oleh para pelaksana PKM bersama perwakilan dari mitra pengabdian yaitu BPCB Jawa Timur melalui radio fikom UC https://ucfikom.radiowebsite.co/ Radio fikom dipilih 
sebagai media diseminasi karena demografi pendengarnya adalah remaja sesuai dengan target audiens buku candi Pustaka.

\section{DAFTAR PUSTAKA}

Alvini, T., \& Guntur, T. (2014). Perancangan Karakter Antropomorfik Eka Dasa Rudra sebagai Media Pengenalan Folklor Bali. Visual Communication Design, 3(1).

Andi Prastowo. (2011). Panduan Kreatif Membuat Bahan ajar Inovatif Menciptakan Metode Pembelajaran Yang menarik dan Menyenangkan (1st ed.). Diva Press.

Arlena, W. M., \& Kurniasari, N. G. A. K. (2013). Malays, China and Indian Ethnicities: A Case Study of Art and Ethnography Content Analysis and Multiculturalism on Upin-Ipin Animation. Aspikom, 2(1).

bpcb mojokerto. (n.d.). Tugas Pokok dan Fungsi Lembaga.

Hiroyoshi Tsukamoto. (2006). Manga Matrix Create Unique Characters Using the Japanese Matrix System (Vol. 1). Harper Design.

Kotler, P., \& Keller, K. L. (2009). Manajemen Pemasaran (13th ed.). Erlangga.

Mahmud Machfoedz. (2010). Komunikasi Pemasaran Modern. Cakra Ilmu.

Pinandita, S. (2016). Perancangan Novel Grafis "Alice in Wonderland" dengan Menggunakan Gaya Gambar Ligne Claire.

Shinney Sutanto. (2020). Konsep Desain dan Ilustrasi (1st ed.). Universitas Ciputra.

Wardaya, M. (2020). 5 Langkah Mudah Membuat Buku Anak Edisi Cerita Rakyat Indonesia (Vol. 1). Universitas Ciputra. 